\title{
Comparison of Preterm and Term Wharton's Jelly-Derived Mesenchymal Stem Cell Properties in Different Oxygen Tensions
}

\author{
Saloni Balgi-Agarwal ${ }^{a}$ Caitlyn Winter ${ }^{a} \quad$ Alexis Corral $^{a}$ \\ Shamimunisa B. Mustafa ${ }^{a}$ Peter Hornsby ${ }^{b}$ Alvaro Moreira ${ }^{a}$ \\ aDivision of Neonatology MC-7812, Department of Pediatrics, University of Texas Health-San Antonio, \\ San Antonio, TX, USA; ${ }^{\text {b }}$ Department of Cellular and Integrative Physiology, University of Texas Health-San Antonio, \\ San Antonio, TX, USA
}

\section{Keywords}

Mesenchymal stromal cells · Umbilical cord · Regenerative medicine $\cdot$ Neonatology $\cdot$ Hyperoxia $\cdot$ Hypoxia

\begin{abstract}
Mesenchymal stem cells (MSCs) have shown promise as therapeutic agents in treating morbidities associated with premature birth. MSCs derived from the human umbilical cord are easy to isolate and have low immunogenicity and a robust ability to secrete paracrine factors. To date, there are no studies evaluating preterm versus term umbilical cord tissue-derived MSCs. Therefore, our aim was twofold: (1) to compare stem cell properties in preterm versus term MSCs and (2) to examine the impact of oxygen tension on stem cell behavior. Umbilical cord tissue was obtained from 5 preterm and 5 term neonates. The cells were isolated and characterized as MSCs in accordance with the International Society for Cellular Therapy. We exposed MSCs to different oxygen tensions to examine the impact of environmental factors on cell performance. We studied the following stem cell properties: (i) motility, (ii) proliferation, (iii) senescence, (iv) cell viability, (v) colony-forming unit efficiency, and (vi) inflammatory cytokine expression. Under normoxia $\left(21 \% \mathrm{O}_{2}\right)$, cells from preterm and term infants had similar properties. Under hypoxic conditions $\left(1 \% \mathrm{O}_{2}\right)$, term MSCs had better cell proliferation;
\end{abstract}

however, cells exposed to hyperoxia $\left(90 \% \mathrm{O}_{2}\right)$ had the slowest motility and lowest cell viability $(p<0.05)$. There was no difference in the expression of senescence or cytokine expression between the groups. The term cells demonstrated more colony-forming efficiency than the preterm cells. In sum, our preliminary findings suggest that MSCs derived from term and preterm umbilical cords have similar characteristics, offering the potential of future autologous/allogeneic MSC transplants in neonates.

(c) 2018 S. Karger AG, Basel

\section{Introduction}

Human umbilical cord-derived mesenchymal stem cells (MSCs) have recently shown promise as potential therapeutic agents in treating medical conditions in preterm infants [Chang et al., 2014; Cotten et al., 2014]. These cells are attractive for clinical use due to their ease of isolation, lack of ethical constraints, and noninvasive retrieval [Forraz and McGuckin, 2011]. Unlike cord blood, the umbilical cord is considered medical waste and typically discarded after birth. Wharton's jelly-derived MSCs (WJ-MSCs) are, therefore, a novel opportunity to create a therapeutic product from an unused resource. Additionally, studies have found that umbilical cord-

\section{KARGER}

(c) 2018 S. Karger AG, Basel

E-Mail karger@karger.com

www.karger.com/cto
Alvaro Moreira, MD, MSc

University of Texas Health-San Antonio

7703 Floyd Curl Drive

San Antonio, TX 78229 (USA)

E-Mail moreiraa@uthscsa.edu 


\begin{tabular}{ll}
\hline Abbreviations used in this paper \\
\hline APC & allophycocyanin \\
CFU & colony-forming unit \\
Cy & cyanine \\
DMEM & Dulbecco's modified eagle medium \\
FBS & fetal bovine serum \\
FITC & fluorescein isothiocyanate \\
HPC & hematopoietic progenitor cell \\
ICAM & intercellular adhesion molecule \\
IL & interleukin \\
IP-10 & interferon $\gamma$-induced protein 10 \\
MCP & monocyte chemotactic protein \\
MEM & minimum essential medium \\
MIP & macrophage inflammatory protein \\
MSC & mesenchymal stem cell \\
PBS & phosphate-buffered saline \\
PE & phycoerythrin \\
PerCP & peridinin chlorophyll protein-cyanin \\
PCR & polymerase chain reaction \\
RANTES & regulated upon activation normal T cell \\
& expressed and secreted \\
SA- $\beta-$ Gal & senescence-associated $\beta$-galactosidase \\
TIMP & tissue inhibitor metalloproteinase \\
UT & University of Texas \\
WJ-MSC & Wharton's jelly-derived MSC \\
\hline
\end{tabular}

derived MSCs have greater proliferative capacity when compared to other adult stem cell sources and have a decreased risk of immune rejection [Weiss and Troyer, 2006; Hass et al., 2011].

Understanding the factors that affect stem cell growth and performance is critical to maximizing their utility for regenerative medicine. In this respect, significant gaps remain before applying cord-derived MSCs to clinical practice. For example, current evidence suggests that there may be a correlation between stem cell age and ability to elicit a therapeutic response [Duscher et al., 2014; Li et al., 2011]. Researchers have shown that aged (or senescent) stem cells have reduced capacities for migration, modulation of anti-inflammatory responses, and impaired differentiation potential compared to young stem cells [Bustos et al., 2014; Turinetto et al., 2016]. In contrast, Markel et al. [2009] found that bone marrow stem cells derived from adults or aged subjects improved post-ischemic myocardial recovery, while neonatal stem cells did not.

Clearly, the relationship between stem cell source age and regenerative properties is not well understood, and, to date, mostly neonatal and adult stem cells have been compared [Li et al., 2011; Bustos et al., 2014; Duscher et al., 2014; Naaldijk et al., 2015]. Messerli et al. [2013] showed that WJ-MSCs from preterm births can differentiate into neural progenitors in much the same capacity as full-term stem cells. Additionally, studies on hematopoietic progenitor cells (HPCs) indicate that cord blood from preterm deliveries contains a higher percentage of HPCs and that preterm HPCs display a higher clonogenic capacity than full-term cord blood HPCs [Podestà et al., 2015; Wisgrill et al., 2014].

In 2013, Lim et al. [2013] compared the ability of term and preterm human amnion epithelial cells to reduce inflammation and fibrosis in a rodent model of lung injury. Although they found that preterm cells have improved cell yield, viability, and a higher proliferation rate than term cells, their ability to lessen inflammation and fibrosis did not reach those found in the term amnion cells. A more recent study evaluated the efficacy of term versus preterm umbilical cord blood cells in a large-animal model of white matter injury [Li et al., 2017]. The authors found that both preterm and term cord blood cells normalized white matter density and decreased cell death in sheep with hypoxic-ischemic brain injury. However, the mechanisms by which the cells alleviated injury differed: preterm cells decreased tumor necrosis factor- $\alpha$, while term cells abated oxidative stress by regulating the expression interleukin (IL)-10.

Traditionally, MSCs are grown in normoxia (21\% oxygen); however, investigators are now expanding their culture conditions in efforts to optimize their restorative ability [Krinner et al., 2009; Mohyeldin et al., 2010; Bader et al., 2015]. For instance, preconditioning MSCs in hypoxia (1-10\% oxygen) has shown improved regenerative/ reparative properties in animal models of heart, brain, and lung injury [Cruz, and Rocco, 2015; Lan et al., 2015; Wakai et al., 2016; Xu et al., 2016]. These findings build on the logic that in vivo MSCs survive in a "hypoxic" niche where oxygen tensions are usually below $10 \%$. On the other hand, hyperoxia is an important mediator of the most common lung morbidity that develops in preterm infants after prolonged mechanical ventilation.. Therefore, studying umbilical cord MSC properties exposed to hyperoxia and hypoxia reveals the potential impact of environmental factors on cell behavior. Furthermore, it allows further elucidation of the advantages/disadvantages of treating morbidities in preterm and/or term infants with autologous versus allogeneic cell-based products.

In this project, we examined differences in the properties of WJ-MSCs derived from preterm and term infants. We defined preterm babies as those delivered before 37 completed weeks' gestation. Compared to term WJMSCs, we hypothesized that preterm WJ-MSCs (i) would 
display higher proliferative capacity, increased viability, improved motility, and decreased senescence when grown under normoxia, (ii) demonstrate similar proliferative capacity, viability, motility, and senescence after subjection to hyperoxia and hypoxia, and (iii) have a distinct inflammatory cytokine profile.

\section{Materials and Methods}

To investigate the differences between preterm and full-term WJ-MSCs, cells were isolated from fresh human umbilical cords. Once cultured, cells were analyzed for surface antigen markers and differentiated into osteogenic, chondrogenic, and adipogenic lineages. Institutional review board approval was sought at the University of Texas (UT) Health-San Antonio and University Health System; however, since the research did not involve human subjects but just leftover de-identified specimens, the board did not require patient/family consent.

Primary Isolation and Expansion of Umbilical Cord WJ-MSCs

Human umbilical cords were collected after preterm $(n=5)$ or full-term $(n=5)$ delivery. A segment of $5-10 \mathrm{~cm}$ was aseptically cut by newborn nurses prior to routine disposal of the umbilical cord. Segments were conserved on ice in phosphate-buffered saline (PBS) solution (Sigma-Aldrich, St. Louis, MO, USA) supplemented with antibiotics (Gibco, Waltham, MA, USA) until use in the laboratory (within $24 \mathrm{~h}$ ).

Cells were isolated from the umbilical cord WJ using an enzyme digestion method [de Bruyn et al., 2011; Azandeh et al., 2012; Rostamzadeh et al., 2015]. The enzymatic method for cell extraction was chosen over the explant technique for several reasons, e.g., due to the high popularity of this method among other researchers, concern of umbilical tissue detaching and thereby reducing cell migration in the culture dish, a potentially higher risk for plate contamination from intact tissue pieces with comparable cell yield, and excellent success of this method in our laboratory [Salehinejad et al., 2012; Han et al., 2013; Hua et al., 2014; Arutyunyan et al., 2016a].

Briefly, cords were washed in PBS and antibiotic solution to remove residual blood from the vein and arteries. They were then rinsed in $70 \%$ ethanol followed by three more PBS rinses. The cord was longitudinally cut, and WJ was dissected from the cord lining with a surgical blade. Tissue fragments were placed into a $60-\mathrm{mm}$ culture dish (Falcon, Corning, NY, USA) with Eagle's minimum essential medium, a modification (aMEM) (Sigma-Aldrich) supplemented with $1 \%$ antibiotic and antimycotic (Gibco) solution. The tissue was digested in $1 \%$ collagenase (Sigma-Aldrich) at $37^{\circ} \mathrm{C}$ in humidified air with $5 \%$ carbon dioxide for $3 \mathrm{~h}$, at which time $0.15 \%$ hyaluronidase (Sigma-Aldrich) was added, and the mixture was incubated for another hour.

After digestion, the tissue remnants and media were passed through a $40-\mu \mathrm{m}$ cell strainer into a $15-\mathrm{ml}$ conical tube and centrifuged at $500 \mathrm{~g}$ for $5 \mathrm{~min}$. The supernatant was discarded, and the remaining cell pellet was plated into a T-25 culture flask (Corning, NY, USA) with MSC growth media (aMEM with L-glutamine [Gibco] and supplemented with 20\% fetal bovine serum [SigmaAldrich)] and $1 \%$ antibiotic and antimycotic solution).

Preterm vs. Term Wharton's Jelly MSCs
The cultures were then expanded with medium changes every 2-3 days until the cells were harvested and used for experiments. All experiments were conducted at passages 3-6. We adhered to passages 3-6 since previous studies have not shown significant alterations in MSC behavior within this range [Zhuang et al., 2015; Arutyunyan et al., 2016b; Smith et al., 2016].

\section{Differentiation of Umbilical Cord Cells}

Differentiation of cord cells was achieved by culturing cells in lineage-specific media for 21-28 days. Chondrogenesis was achieved using the StemPro chondrogenesis kit (Thermo Fisher, Waltham, MA, USA) per manufacturer's instructions. Chondrogenesis was verified with Alcian blue staining (Sigma-Aldrich). Osteogenesis was achieved using the StemXVivo osteogenesis kit (R\&D Systems, Minneapolis, MN, USA) per manufacturer's instructions. Osteogenic differentiation was confirmed by Alizarin red-S staining (Sigma-Aldrich) for calcium deposits. Adipogenesis was achieved by seeding the cells in $0.5 \mathrm{~mm}$ isobutylmethylxanthine, $200 \mu \mathrm{M}$ indomethacin, $1 \mu \mathrm{M}$ dexamethasone, and $10 \mu \mathrm{g} / \mathrm{ml}$ of insulin in low-glucose DMEM (Invitrogen) with 10\% FBS [Scott et al., 2011]. Adipogenesis was confirmed by oil red-O staining (Sigma-Aldrich) for lipid droplets.

\section{Surface Antigen Expression of Cord Cells}

Flow cytometry was performed with the assistance of the flowcytometric core facilities at UT Health-San Antonio. The following monoclonal antibodies (mouse anti-human) were used for MSC cell surface antigen phenotyping: 7AAD PerCP (peridinin chlorophyll protein)-Cy5.5 (cyanine 5.5), CD 90 BV421 (brilliant violet 421), CD 73 FITC (fluorescein isothiocyanate), CD $146 \mathrm{PE}$ (phycoerythrin), HLA-DR APC (allophycocyanin), CD 117 APC, and CD 79a APC. This combination of surface antigens has been reported in the literature to identify MSCs from hematopoietic stem cells [Hermida-Gómez et al., 2011; Mafi, 2011; Huang et al., 2014; Wu et al., 2016].

Briefly, cells were cultured in regular media, trypsinized, aliquoted, and resuspended at a concentration of $1 \times 10^{6}$ cells $/ \mathrm{mL}$. They were incubated for $30 \mathrm{~min}$ with either conjugated specific antibodies or isotype-matched control mouse IgG at recommended concentrations at $4{ }^{\circ} \mathrm{C}$. Labeled cells were washed, resuspended in PBS, and analyzed on a Becton Dickinson LSR II flow cytometer. The gating was done by using forward and side scatter doublet discrimination to remove debris. Afterwards, gating of doublets was performed to negatively select dead cells and HLA-DR, CD 117, and CD 79A. From this population, we analyzed percent positive cells for each of the following individual markers: CD 90, CD 73, and CD 146. Results were expressed as the mean percentage of positive cells.

\section{Motility of WJ-MSCs}

Motility of WJ-MSCS was analyzed using an in vitro scratch assay modified from Liang et al. [2007]. In brief, cells were plated into 12-well plates and allowed to form a confluent monolayer for $24 \mathrm{~h}$. Cells were then scratched across the wells with a P-200 pipet tip to form an area free of cells. The wells were then rinsed with PBS, and the growth media replaced. Images of the scratches were acquired under light microscopy at $0,4,8$, and $24 \mathrm{~h}$ after disturbance. Scratch size was analyzed using ImageJ software (National Institutes of Health, Bethesda, MD, USA). Three trials were conducted for each cell line. 


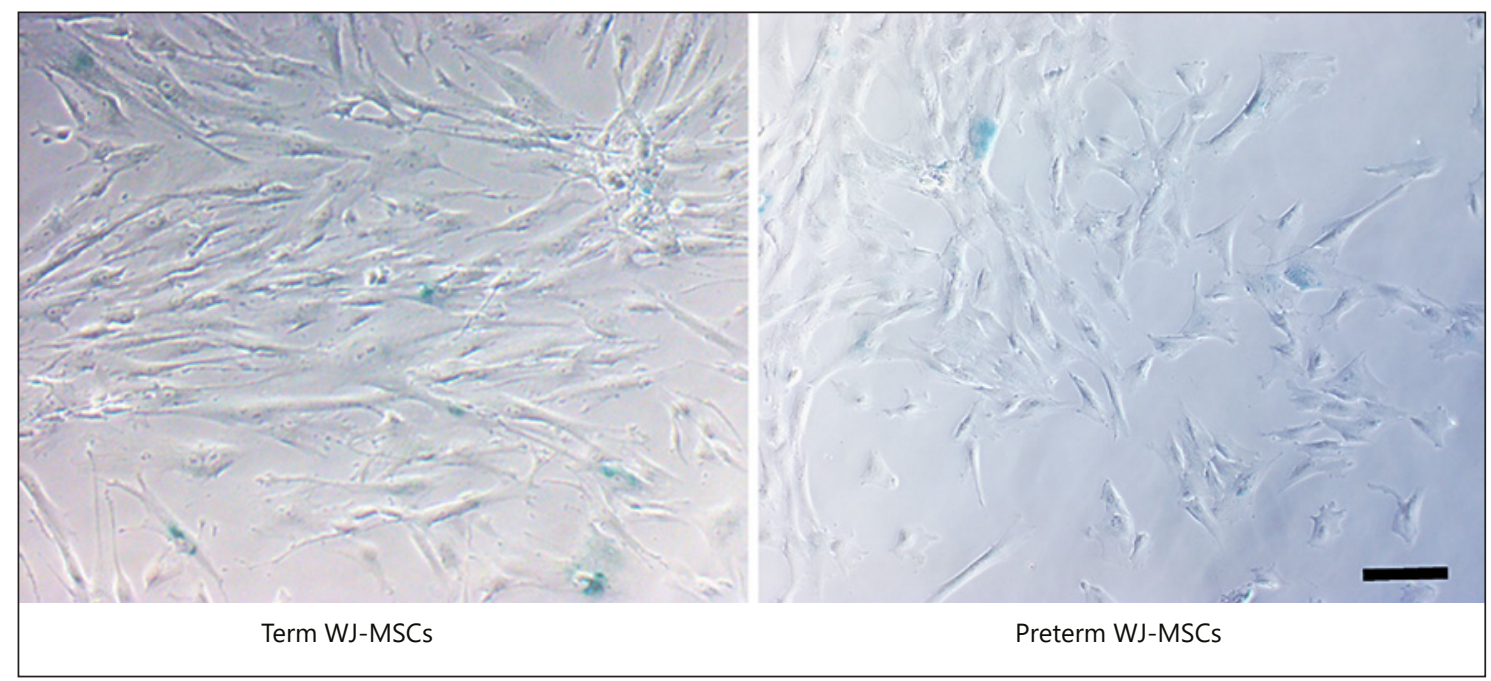

Fig. 1. Senescence expression in preterm and term WJ-MSC. Bar, $40 \mu \mathrm{m}$.

\section{Proliferation of WJ-MSCS}

Proliferation of WJ-MSCs was analyzed using Abcam's Quick cell proliferation kit (Abcam; Cambrigde, MA, USA; MA catalogue \#ab65473) according to the manufacturer's instructions. WJ-MSCs were plated at a density of $4 \times 10^{4}$ cells into each well (repeated in triplicate) of a 96-well flat-bottom tissue culture plate (Falcon) for $24 \mathrm{~h}$. WST-1/ECS solution was added to each well and incubated in standard culture conditions for $2 \mathrm{~h}$. Absorbance was then measured using a microplate reader (BioTek Instruments, Inc., Winooski, VT, USA) at $450 \mathrm{~nm}$ with a reference wavelength of $650 \mathrm{~nm}$. The results were expressed as mean absorbance in nanometers.

\section{Senescence}

Senescence is considered an underlying cause of aging and represents an arrested state of cells. Senescent cells display increased expression of senescence-associated $\beta$-galactosidase (SA- $\beta$-Gal) activity.

Senescence of the cells was analyzed using Abcam's senescence detection kit (catalogue \#ab65351). This kit is designed to histochemically detect SA- $\beta$-Gal activity in cultured cells and tissue sections. Specifically, WJ-MSCs were plated at a density of $2 \times 10^{5}$ cells into each well of a 12-well plate (replicated in duplicate). The cells were then fixed with $0.5 \mathrm{~mL}$ of fixative solution for 10-15 min at room temperature. Half a milliliter of the staining solution mix was then added to each well, and it was incubated at $37^{\circ} \mathrm{C}$ overnight. Cells were then observed under a microscope (Olympus IX50, $\times 10$ magnification) for development of blue color (Fig. 1). Two random images were obtained per well and were analyzed using ImageJ software.

\section{Cell Viability}

Cell viability was assessed by calculating the percentage of live cells at $21 \%$ oxygen. Cells were plated at a density of 150 cells per well of a 6-well plate (repeated in duplicate). Cells were then trypsinized with $1 \mathrm{~mL}$ of trypsin (TrypLE express enzyme, Gibco) per well. After deactivation of trypsin with $1 \mathrm{~mL}$ of growth media, the cell suspension was centrifuged at $500 \mathrm{~g}$ for $5 \mathrm{~min}$. Cell numbers were automated using a Countess cell counter (Countess II FL automated cell counter; Thermo Fisher Scientific).

\section{Colony-Forming Efficiency of WJ-MSCs}

Colony-forming efficiency of WJ-MSCs was analyzed using a modified colony-forming unit (CFU) assay from Alt et al. [2011]. WJ-MSCs (150) were plated into a $60-\mathrm{mm}$ culture dish and maintained for 14 days under standard culture conditions with medium changes every 2-3 days. After 14 days, cultures were stained with crystal violet (Sigma Aldrich), and colonies were counted. CFU efficiency was calculated by dividing the number of colonies per dish by the number of cells (150) seeded per dish multiplied by $100 \%$. Cultures were repeated thrice for each cell line.

\section{Exposure to Hyperoxia $\left(90 \% \mathrm{O}_{2}\right)$ and Hypoxia $\left(1 \% \mathrm{O}_{2}\right)$}

After isolation and characterization of preterm and term WJMSCs, studies were repeated with oxygen concentrations at 90 or $1 \%$. An airtight modular incubator chamber was used to maintain oxygen tension (Billups-Rothenberg, Del Mar, CA, USA), and a digital oxygen analyzer (Hudson RCI, Teleflex, Morrrisville, NC, USA) was used to monitor the concentration of $\mathrm{O}_{2}$ inside the chamber. The 24-hour time point was chosen based on viability testing (in triplicate) of the cells at different time points in hyperoxia (online suppl. Fig. 1; for all online suppl. material, see www. karger.com/doi/10.1159/000489256).

\section{Cytokine Secretion Profiling by Cytokine Antibody Array}

Cytokine profiling of the cells was performed using the $\mathrm{Hu}$ man Inflammation Antibody Array-Membrane (\#ab134003; Abcam). This array analyses human protein samples for 40 different inflammatory cytokines. Array membranes were incubated for 30 min in $2 \mathrm{ml}$ of blocking buffer supplied with the kit. Following this, they were further incubated for $60 \mathrm{~min}$ at room temperature with $200 \mu \mathrm{g}$ of protein from each cell sample. Biotin-conjugated 


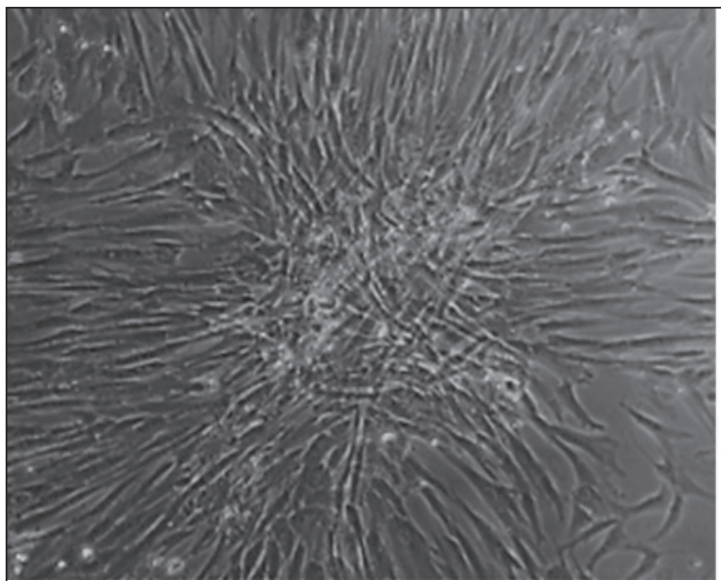

Preterm WJ-MSCs

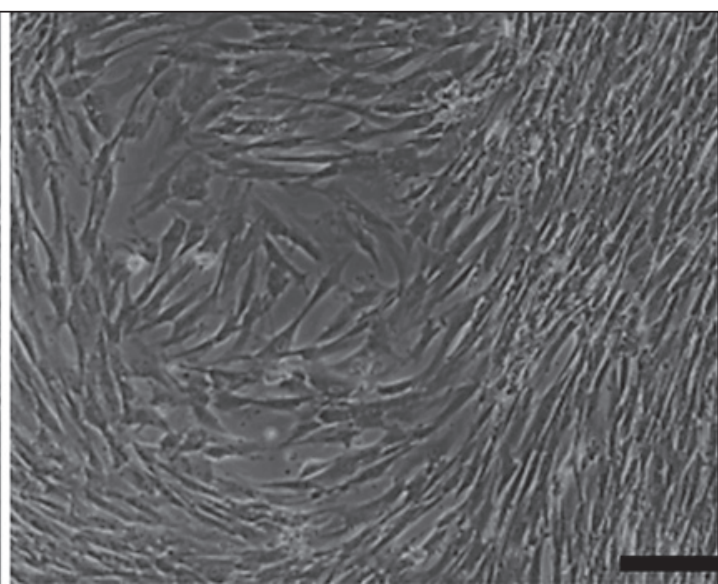

Term WJ-MSCs

Fig. 2. Classic fibroblast-like appearance of MSCs in preterm (gestational age: 27 weeks) and term (37-42 weeks) umbilical cord Wharton's jelly tissue. $\times 10$. Bar, $40 \mu \mathrm{m}$.

anti-cytokines $(1 \mathrm{ml})$ were then added to each membrane after a thorough wash. This was succeeded by an overnight incubation at $4{ }^{\circ} \mathrm{C}$ and followed by incubation with a 1:2,000 dilution of HRPconjugated streptavidin for $60 \mathrm{~min}$ at room temperature. The proteins were detected by chemiluminescence Western blot, and signals were captured on X-ray films (Denville Scientific, Holliston, MA, USA), scanned at high resolution, and quantified using ImageJ software.

\section{Statistical Analysis}

Data was analyzed using Microsoft Excel and STATA v.13 (College Station, Texas). Student's $t$ test and ANOVA were performed as applicable. $p<0.05$ was considered significant. Data are presented as means \pm SEM.

\section{Results}

Characteristics of the Preterm and Term WJ-MSCs

The range of gestational ages for the umbilical cords of preterm infants was 25-30 weeks' gestation while cords of term infants ranged between 37 - and 42 weeks (data summarized in Table 1).

The mean gestational age for the preterm cohort was $28 \pm 2$ weeks (70\% term equivalent). Average cell viability for preterm and term WJ-MSCs was similar.

\section{Cell Morphology and Plastic Dish Adherence}

Figure 2 depicts the spindle-shaped morphology characteristically observed in preterm and term WJ-MSCs as well as the adherence to plastic.
Table 1. Gestational age of the preterm and term WJ-MSCs

\begin{tabular}{llll}
\hline Group & $\begin{array}{l}\text { Gestation, } \\
\text { weeks }\end{array}$ & $\begin{array}{l}\text { Mature } \\
\text { cells, \% }\end{array}$ & $\begin{array}{l}\text { Viability, } \\
\%\end{array}$ \\
\hline Preterm 1 & 25 & 62 & 96 \\
Preterm 2 & 27 & 67 & 95 \\
Preterm 3 & 28 & 70 & 96 \\
Preterm 4 & 28 & 70 & 97 \\
Preterm 5 & 30 & 75 & 96 \\
\hline Term 1 & $37-42$ & $90-100$ & 92 \\
Term 2 & $37-42$ & $90-100$ & 94 \\
Term 3 & $37-42$ & $90-100$ & 96 \\
Term 4 & $37-42$ & $90-100$ & 99 \\
Term 5 & $37-42$ & $90-100$ & 97 \\
\hline
\end{tabular}

\section{Differentiation}

Both preterm and term WJ-MSCs demonstrated the ability to differentiate into osteocytes, chondrocytes, and adipocytes upon in vitro stimulation (Fig. 3).

\section{Flow Cytometry}

Preterm and term WJ-MSCs expressed CD $73>95 \%$, CD90 >95\%, and CD $146>90 \%$. Neither cell type expressed CD 79, CD 117, or HLA-DR > 5\% (Fig. 4). 


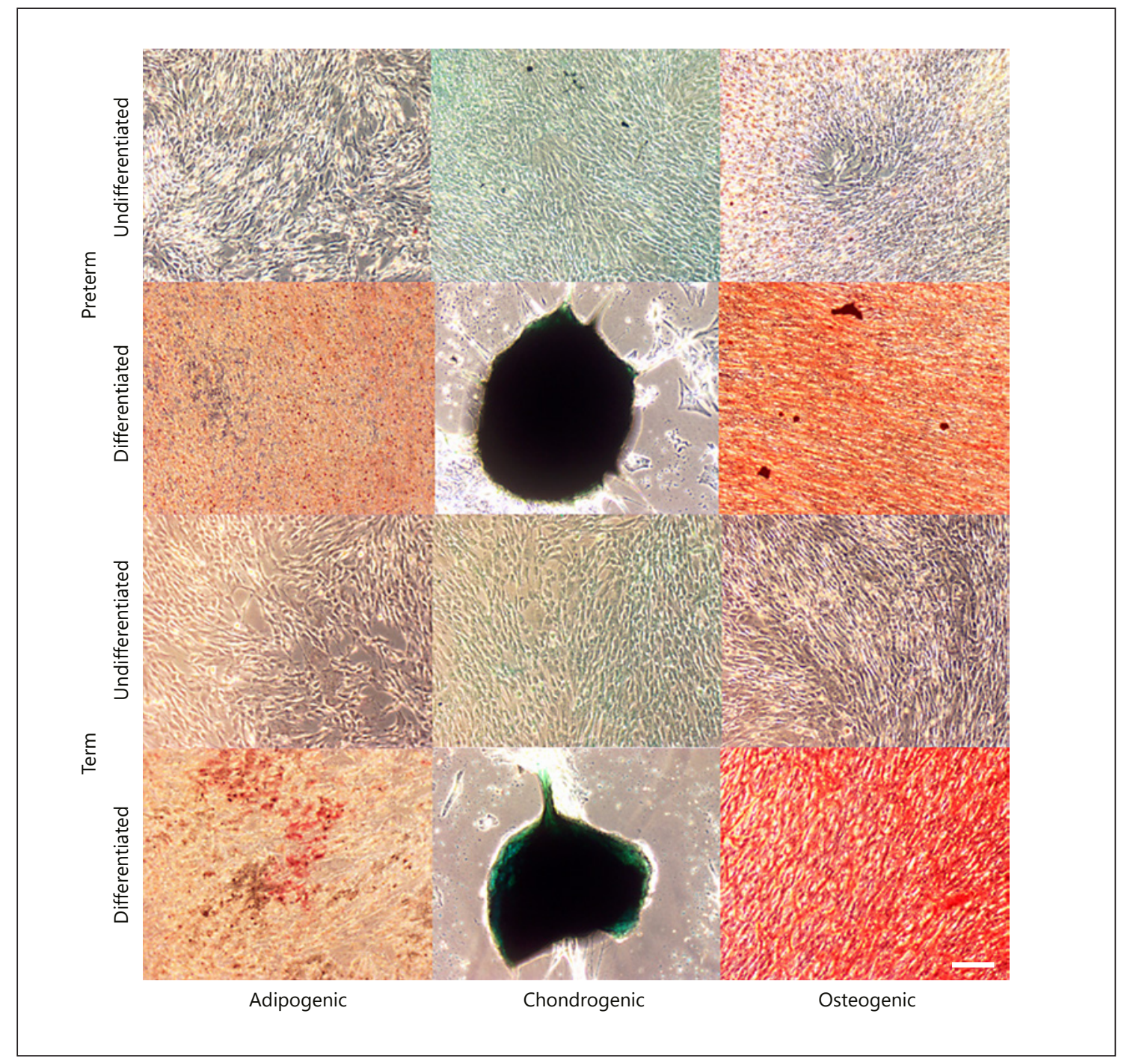

Fig. 3. Multilineage differentiation of preterm and term WJ-MSCs into adipogenic (oil red O stain; left), chondrogenic (Alcian blue; middle), and osteogenic (Alizarin red stain; right) cells. $\times 10$. Bar, $40 \mu \mathrm{m}$.

\section{Motility}

Table 2 summarizes the results of the motility test, while Figure 5 shows representative images of the test in progress.

There were no significant differences in cell motility between the term and the preterm cells in normoxia, hyperoxia, or hypoxia 4 and $8 \mathrm{~h}$ after the scratch injury. Both cell types closed most of the scratch area by $24 \mathrm{~h}$ after disturbance, although small areas remained free of cells in a few of the trials.

A one-way ANOVA was conducted to determine if motility was different according to oxygen tension groups.
There was a statistically significant difference between groups as determined by one-way $\operatorname{ANOVA}(\mathrm{F}(2,27)=$ $4.69, \mathrm{p}=0.02)$. A Tukey post-hoc test revealed that motility was higher in the normoxic group compared to the hyperoxic group $(31.6 \pm 10.4 \%, \mathrm{p}=0.01)$. However, there was no difference between normoxic and hypoxic groups $(18.1 \pm 10.4 \%, p=0.21)$, or hypoxic and normoxic groups $(13.6 \pm 10.4 \%, \mathrm{p}=0.4)$.

There were significant differences within the term cell lines when cultured in normoxia versus hyperoxia (oneway ANOVA $(F(2,12)=4.16, p=0.04)$. Eight hours after the scratch, the term normoxic group had $62.6 \pm 7.4 \%$ 


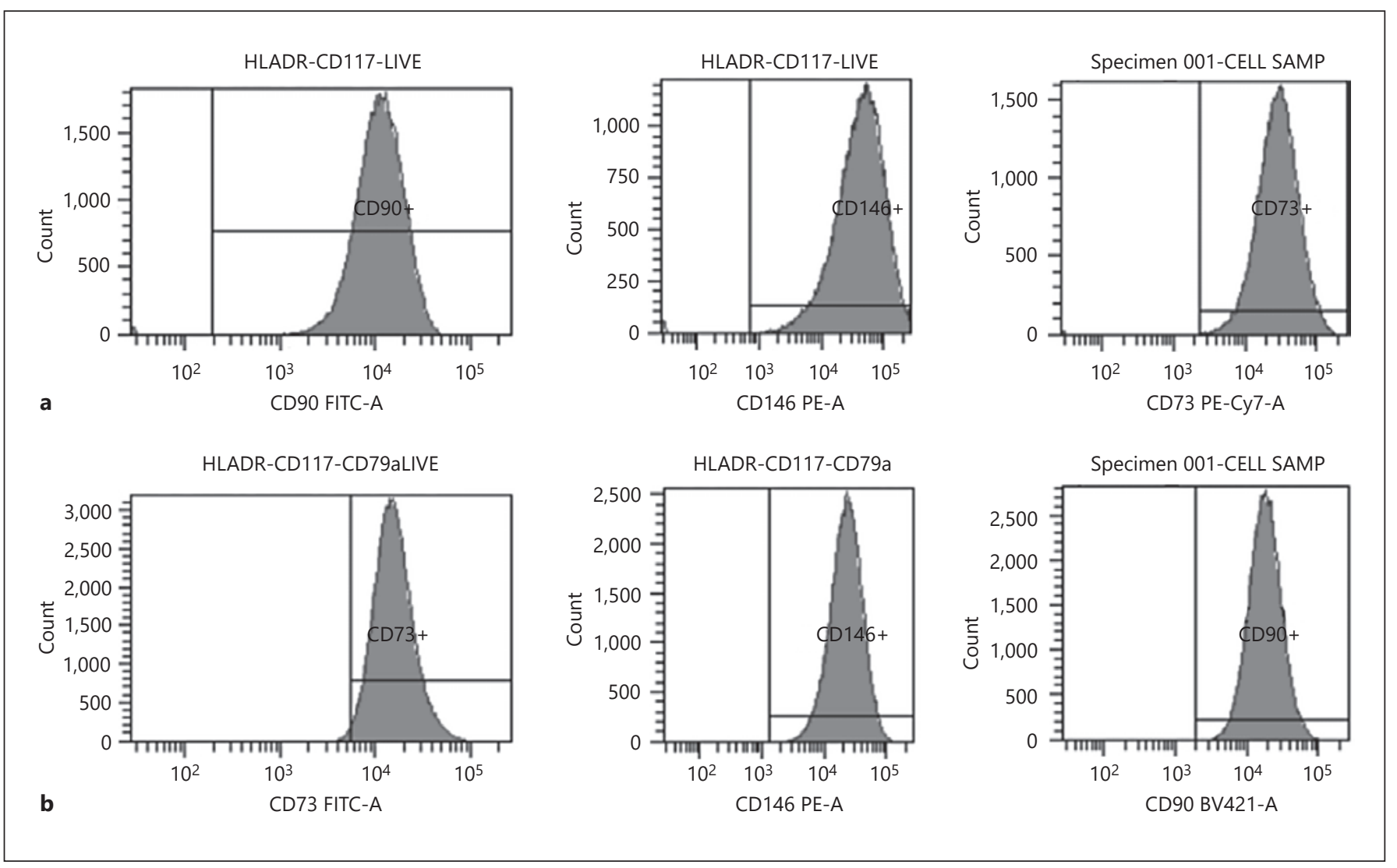

Fig. 4. Flow cytometry of surface antigen markers on sample preterm and term WJ cells.

closure while the hyperoxic injury had only $28.4 \pm 6.0 \%$ wound closure $(p=0.04)$.

A trend was appreciated between the term hyperoxic and hypoxic exposures at $8 \mathrm{~h}$, but it did not reach significance (28.4 \pm 6.0 vs. $56.0 \pm 12.0 \%$, respectively; $p=0.07)$.

\section{Proliferation}

Figure 6 summarizes the results of the proliferation test.

Preterm and term WJ-MSCs had very similar proliferation rates in normoxic and hyperoxic conditions.

However, the highest proliferation was in term cells exposed to hypoxia $(p<0.05$ compared to both groups in normoxia and hyperoxia). The preterm WJ-MSCs also had improved cell proliferation in hypoxia, but the changes did not reach significance.

\section{Senescence}

Figure 7 demonstrates no differences between the groups in SA- $\beta$-gal staining in normoxia, hyperoxia, or hypoxia.

Preterm vs. Term Wharton's Jelly MSCs
Table 2. Motility studies comparing preterm and term WJ-MSCs

\begin{tabular}{lll}
\hline & \multicolumn{2}{l}{ Wound closed after scratch injury, \% } \\
\cline { 2 - 3 } & preterm $(n=5)$ & term $(n=5)$ \\
\hline Normoxia $\left(21 \% \mathrm{O}_{2}\right)$ & & \\
$4 \mathrm{~h}$ & $41 \pm 11$ & $31 \pm 5$ \\
$8 \mathrm{~h}$ & $67 \pm 14$ & $62 \pm 7$ \\
Hyperoxia $\left(90 \% \mathrm{O}_{2}\right)$ & & \\
$4 \mathrm{~h}$ & $17 \pm 5$ & $12 \pm 3$ \\
$8 \mathrm{~h}$ & $38 \pm 12$ & $28 \pm 6$ \\
Hypoxia $\left(1 \% \mathrm{O}_{2}\right)$ & & \\
$4 \mathrm{~h}$ & $23 \pm 5$ & $25 \pm 8$ \\
$8 \mathrm{~h}$ & $37 \pm 7$ & $56 \pm 12$ \\
\hline
\end{tabular}

Means \pm SEM. 


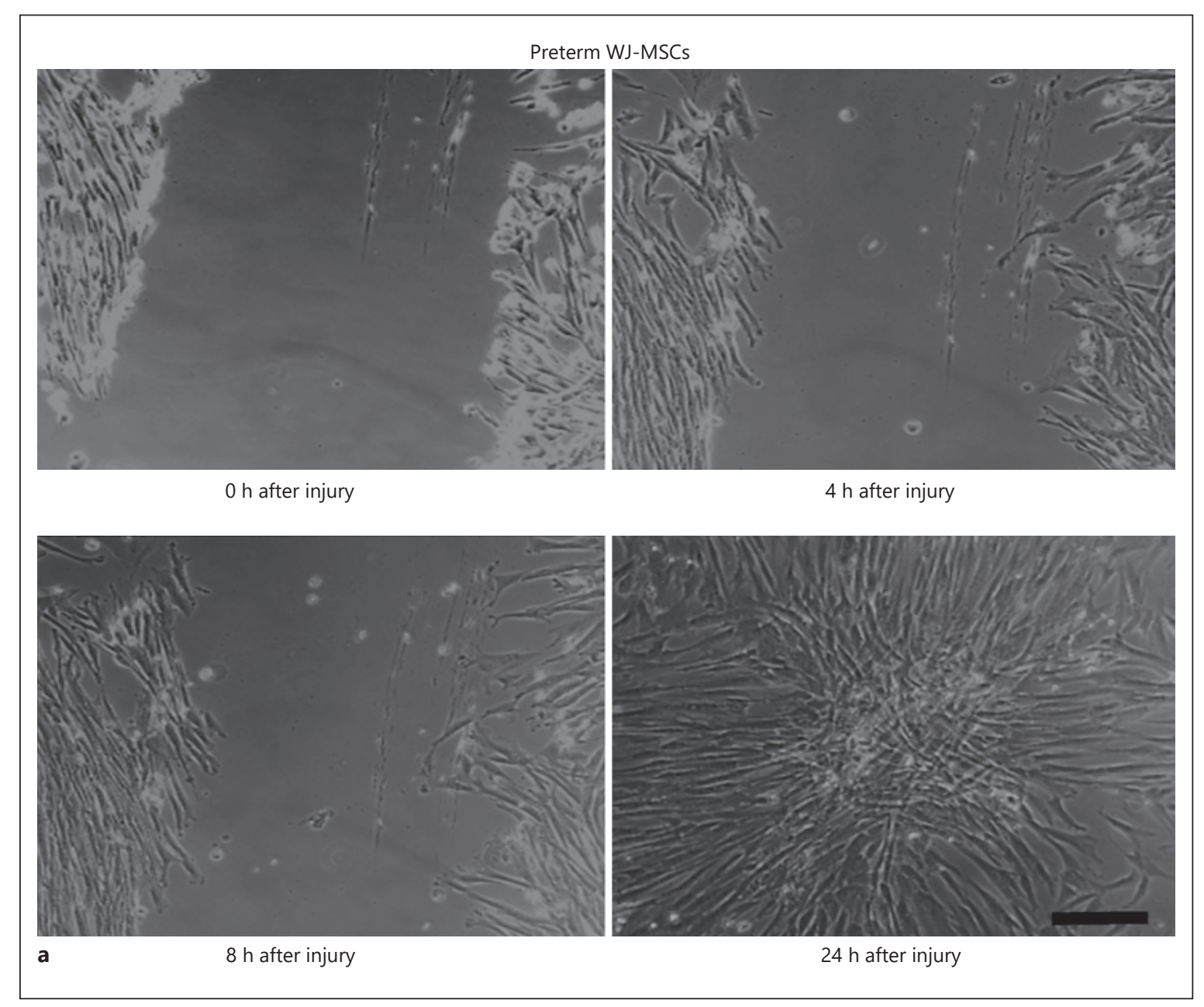

Fig. 5. Motility of preterm (a) and term (b) WJ-MSCs after in vitro scratch wound at 0-, 4-, 8-, and 24-h time points. $\times 10$. Bar, $40 \mu \mathrm{m}$.

(Figure continued on next page.)

Table 3. Cell viability in preterm and term WJ-MSCs

\begin{tabular}{lll}
\hline & \multicolumn{2}{l}{ Live cells (means \pm SEM), \% } \\
\cline { 2 - 3 } & preterm $(n=5)$ & term $(n=5)$ \\
\hline Normoxia $\left(21 \% \mathrm{O}_{2}\right)$ & & \\
$\quad$ Before & $95 \pm 0.5$ & $95 \pm 1.2$ \\
$\quad$ After & $94 \pm 2.3$ & $95 \pm 2.0$ \\
Hyperoxia $\left(90 \% \mathrm{O}_{2}\right)$ & & \\
$\quad$ Before & $95 \pm 0.5$ & $95 \pm 1.2$ \\
$\quad$ After & $89 \pm 1.8$ & $87 \pm 5.6$ \\
Hypoxia $\left(1 \% \mathrm{O}_{2}\right)$ & & \\
$\quad$ Before & $95 \pm 0.5$ & $95 \pm 1.2$ \\
$\quad$ After & $87 \pm 6.7$ & $89 \pm 9.8$ \\
\hline
\end{tabular}

Cell Viability after Hyperoxia and Hypoxia

Preterm and term WJ-MSCs had similar viability in normoxia, hyperoxia, and hypoxia.

Yet, when both preterm and term cells were grouped $(n=10)$, hyperoxia showed a reduction in viability $(94.9 \pm 1.92$ vs. $88.6 \pm 4.0 \%$ in normoxia, $p=0.03$; data shown in Table 3 ).

\section{Colony-Forming Efficiency}

Colony-forming efficiency was higher in the term $(24.7 \pm 3.2 \%)$ than the preterm cells $(15.2 \pm 3.0 \% ; p<0.05$; data depicted in Fig. 8).

\section{Inflammatory Cytokines}

There were no significant differences in the inflammatory cytokine profile expression of the two populations in 


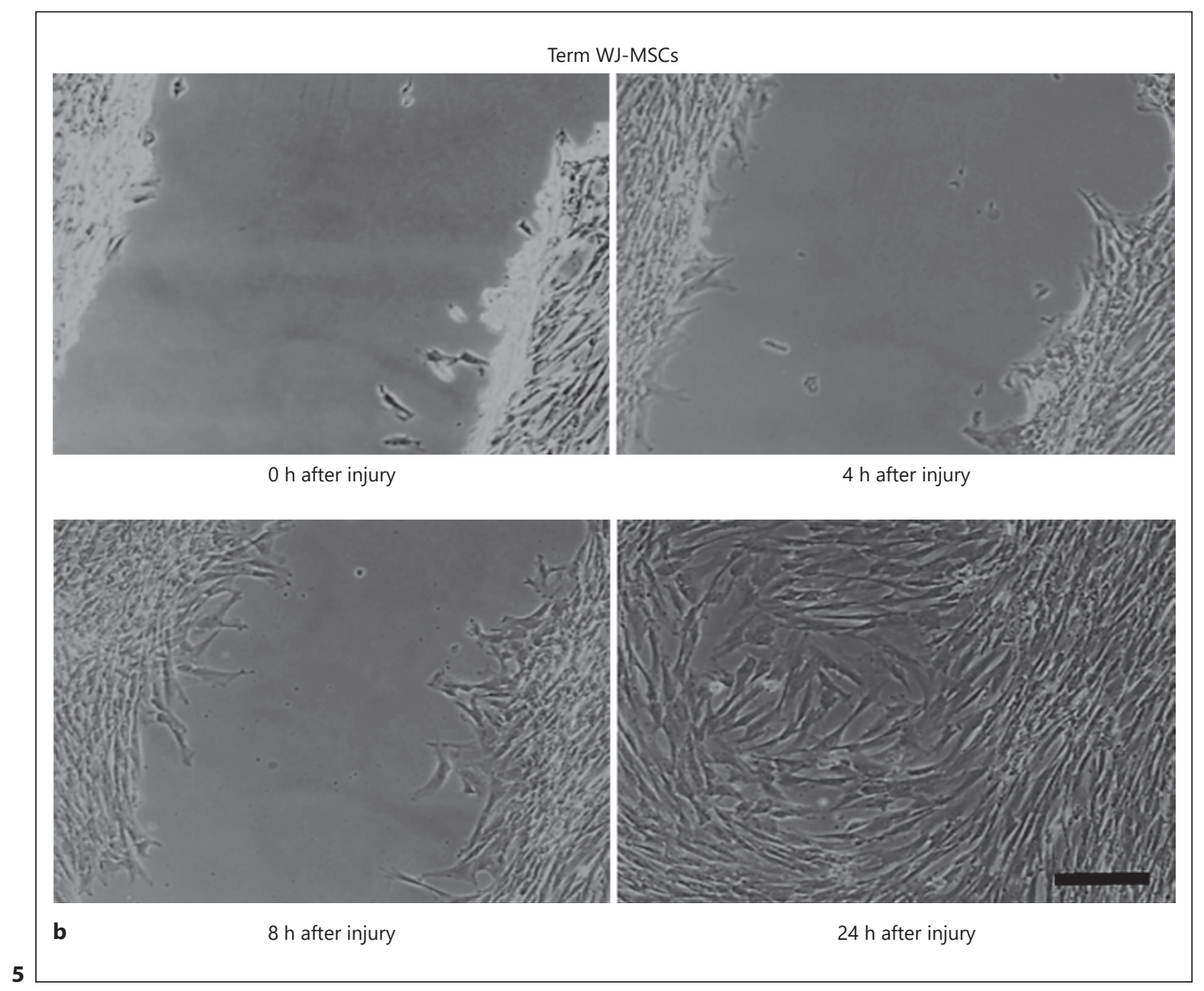

normoxia. Of note, 3 cytokines were strongly expressed in the array for WJ-MSCs: Interferon $\gamma$-induced protein 10 (IP-10), macrophage inflammatory protein (MIP)-1 $\beta$, and monocyte chemotactic protein 1 (MCP-1). None of the 10 samples expressed the following cytokines: IL-4, IL-7, IL-10, IL-11, IL-13, and IL-17, granulocyte and granulocyte macrophage colony-stimulating factor, monokine induced by interferon $\gamma$, T-lymphocyte-secreted protein I-309, and MIP-1 $\delta$ (data are summarized in Fig. 9).

\section{Discussion}

The perinatal period offers an opportune time to collect tissues (in a noninvasive approach) that are rich in hematopoietic cells and MSCs [Weiss, and Troyer, 2006; Messerli et al., 2013; Yousefifard et al., 2016; Moreira et al., 2017]. In this study, we sought to evaluate character- istics of umbilical cord cells isolated from preterm and term infants. Our results suggest that MSCs derived from term and preterm neonatal umbilical cords have similar morphologies, adhere to plastic, express similar surface antigen markers, and can differentiate into multiple lineages.

Similar to findings by Duscher et al. [2014], age did not play a significant role in MSC proliferative capacity. Their study examined the replicative ability of adipose-derived MSCs in young adult wild-type mice versus an aged cohort. Interestingly, we found hypoxia stimulated proliferation in term WJ-MSCs. These findings are substantiated in studies involving hematopoietic and neural stem cells grown in hypoxic niches. The investigators speculate lower oxygen tensions reduce oxidative stress and thus DNA injury [Hubbi and Semenza, 2015].

Another theory explaining improved term cell replication in hypoxia may be a result of the higher number of mitochondria observed in relation to preterm MSCs 


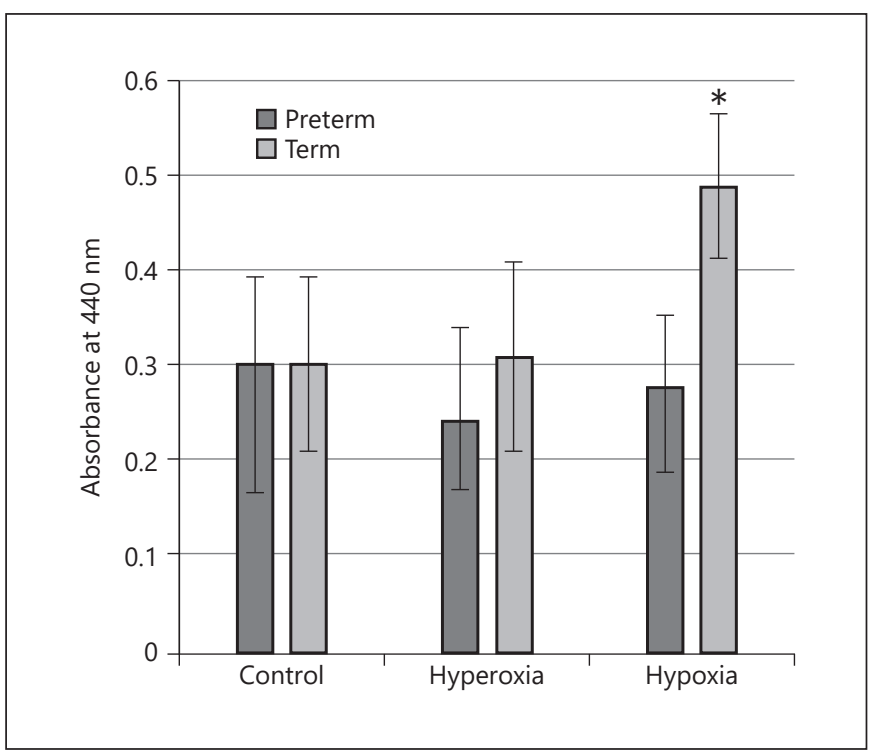

Fig. 6. Cell proliferation of preterm and term WJ-MSCs. ${ }^{*} \mathrm{p} \leq 0.05$.

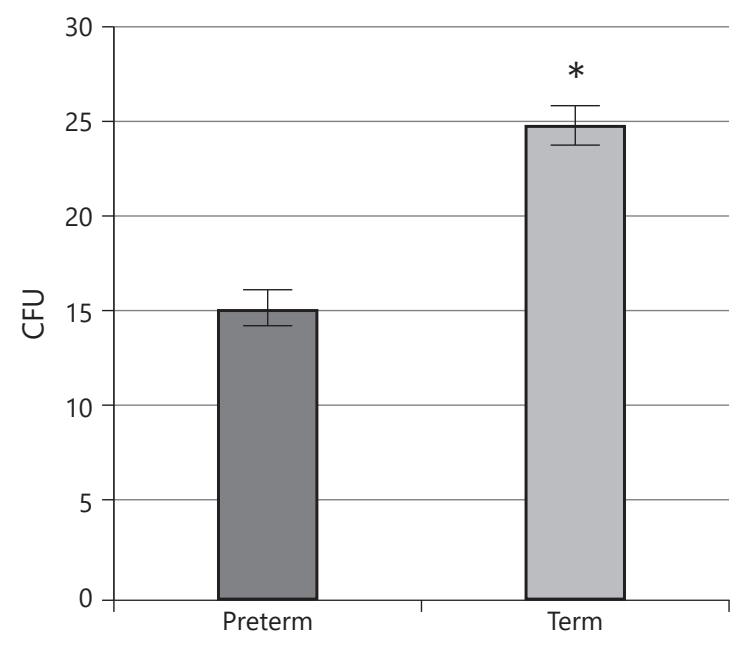

Fig. 8. Colony-forming unit (CFU) in preterm versus term WJMSCs. ${ }^{*} \mathrm{p} \leq 0.05$.

[Panfoli et al., 2015]. More mitochondria allow for a greater efficiency of the electron transport chain and therefore increase cell proliferation [Antico Arciuch et al., 2012]. Furthermore, hypoxia promotes mitochondrial enzymes known to decrease oxygen consumption [Ghafourifar and Cadenas, 2005].

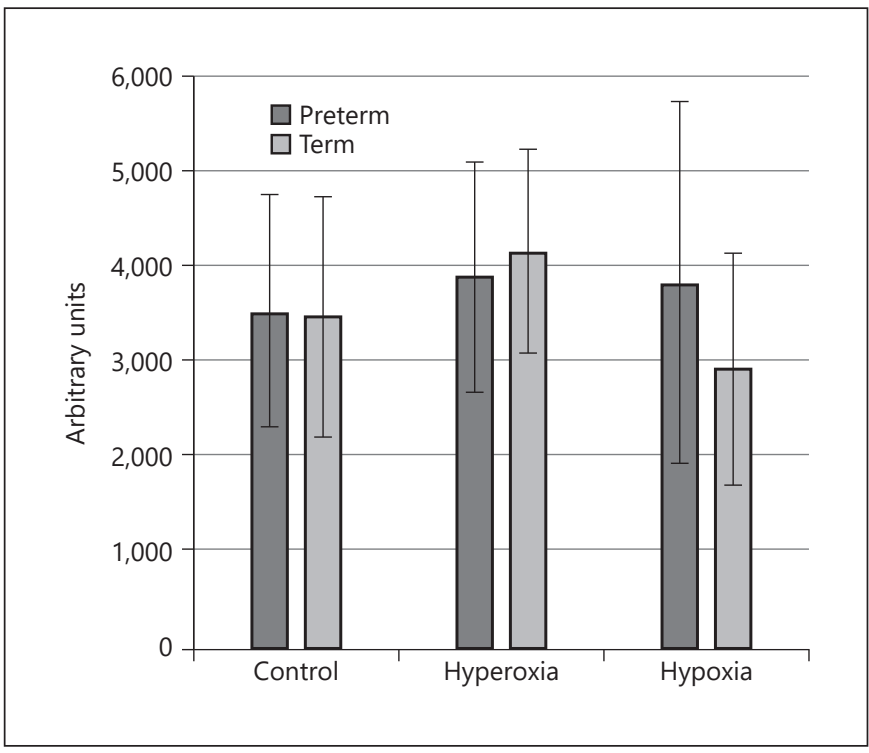

Fig. 7. Senescence of preterm and term WJ-MSCs after 21, 90, and $1 \%$ oxygen exposure. $\times 10$. Bar, $40 \mu \mathrm{m}$.

Studies by Naaldijk et al. [2015] demonstrated comparable migration rates in neonatal and adult MSCs. Our migration studies had similar findings, except we appreciated a reduction in motility in term hyperoxic MSCs. Investigations using endothelial cells grown under hyperoxia led to a decrease in motility that was attributed to a lower expression of CXCR4 [Uno et al., 2007; do Carmo et al., 2010]. In contrast, Pendyala et al. [2009] showed an increase in cell motility with hyperoxia; however, their experiments employed different cells, duration of hyperoxia, and at baseline their cells appeared less motile than MSCs.

The CFUs were decreased in preterm WJ-MSCs. Although the study by Wyrsch et al. [1999] found a higher proliferative ability in preterm umbilical cord blood cells, term cord blood cells had a slightly greater colony formation when grown in media without growth factors. On the other hand, Wisgrill et al. [2014] and Podestà et al. [2015] observed better clonogenicity in preterm umbilical cord blood progenitor cells. A plausible explanation for the decreased reproductive potential in term MSCs may be that they differentiated quicker [Franken et al., 2006; Boyette et al., 2014]. Also, since the current study isolated MSCs from the cord tissue rather than the blood, there could be site-specific differences explaining the clonogenic potential of MSCs across gestational ages.

There was no difference in senescence in both groups. Changes in senescence could have potentially hindered 


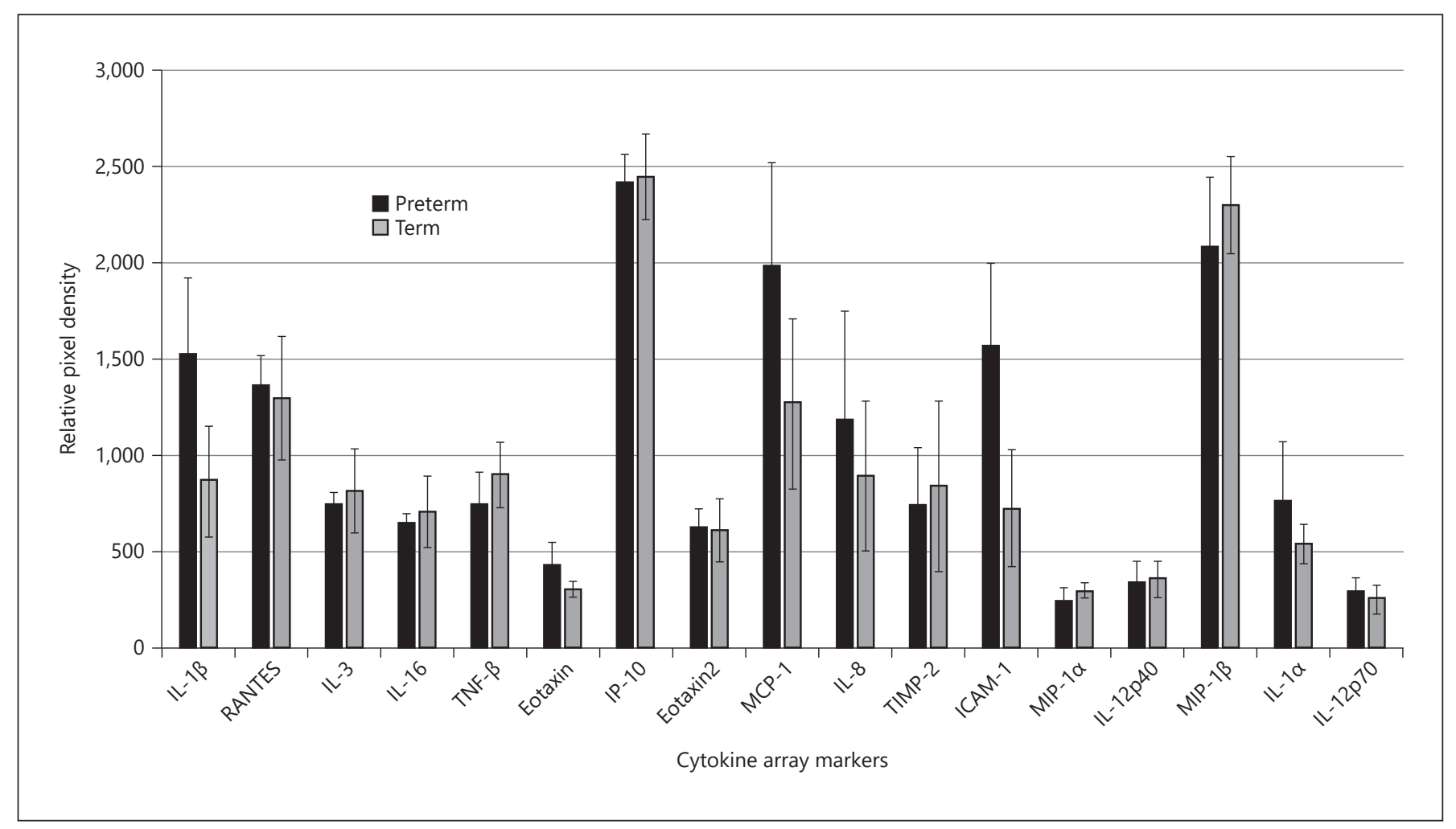

Fig. 9. Inflammatory cytokine expression of the preterm and term WJ-MSCs (see list of abbreviations for further information). Means \pm SEM.

other cell processes, including cell growth, migration, and differentiation [Turinetto et al., 2016]. Bustos et al. [2014] reported no influence of hyperoxia on senescence in preterm and term MSCs. There are various other ways for assessing senescence in cells besides $\beta$-Gal. They include studying cyclin-dependent kinase inhibitors (p16 and p21), cytoskeleton markers, and retinoblastoma protein [Turinetto et al., 2016]. Cells are also more prone to senescence under higher production of reactive oxygen species and/or lower antioxidant enzymes. Studies measuring oxidative stress in preterm versus term WJ-MSCs showed that preterm MSCs have higher production of reactive oxygen species, which may be due to mitochondrial immaturity [Ravera et al., 2017]. However, the study did not measure markers of senescence. Future studies should also incorporate apoptosis as a measure in injured preterm and term MSCs.

Exposure to hyperoxia caused a decrease in viability when we grouped all cells. Masalunga et al. [2007] described an increase in necroptosis and apoptosis in progenitor cells treated with chronically elevated oxygen levels. Analogous to our study, Aly et al. [2012] found com-

Preterm vs. Term Wharton's Jelly MSCs parable viability rates of MSCs isolated from preterm and term cord cells under normal culture conditions.

The inflammatory profile of WJ-MSCs from preterm and term populations were alike. Sullivan et al. [2002] hypothesized that the serum concentrations of leukocyte chemokines eotaxin, RANTES (regulated upon activation normal T cell expressed and secreted), and MIP-1a would be lower in preterm infants. They concluded that concentrations of $\alpha$ and $\beta$ chemokines tested from preterm infants were equivalent to those measured in term neonates. Additionally, in a study involving 34 healthy preterm/term newborns, investigators examined serum cytokines during the first week of life. No difference between the groups was detected in the concentration of RANTES, interleukin- $1 \beta$, eotaxin, and MIP- $1 \beta$. Contrasting to umbilical cord blood monocytes, cells from our study did not show a decrease in IL-12 subunits in the preterm samples [Lavoie et al., 2010; Pérez et al., 2010].

Interestingly, there was a remarkable expression of MIP-1 $\beta$, MCP-1, and IP-10 in both preterm and term WJ-MSCs. In human patients with critical limb ischemia, MIP-1 $\beta$ measurements were significantly higher in pa- 
tients who responded to MSC treatment. The investigators ascribe the higher recruitment of macrophages and endothelial cells (by MIP-1 $\beta$ ) as an explanation for ischemic healing [Altaner et al., 2013]. Boomsma and Geenen [2012] revealed that the paracrine expression of MCP-1 and MIP- $1 \beta$ from MSCs led to improved wound healing by stimulating cell migration and inhibiting apoptosis. A comparative analysis study of WJ-MSCs showed IP-10 suppressedinflammationafterinduction withinterferon- $\gamma$ via regulation of $\mathrm{T}$ and natural killer cells [Mao et al., 2010].

Limitations to this study include the small sample size of preterm and term umbilical cords. A larger population may provide stronger arguments in phenotypic and functional differences. Another drawback is that the gestational age in the preterm umbilical cords approached 30 weeks and the neonatal population that would gain the most benefit from future stem cell therapies are those with the highest risk for morbidity and mortality - infants $<28$ weeks' gestation. Furthermore, data on maternal characteristics would have benefitted this study, being that maternal health can impact umbilical cord cell behavior [Kim et al., 2015].

The umbilical cord WJ is a promising and emerging tissue source for future opportunities in regenerative medicine. Overall, the present study demonstrated that preterm and term isolated WJ-MSCs are comparable when cultured at $21 \% \mathrm{O}_{2}$. However, exposure to hyperoxia was noted to impair the motility and cell viability of both populations. Moreover, term WJ-MSCs had higher proliferative capacity after exposure to hypoxia. Translationally, these results suggest that in the future neonates may be treated, and potentially have similar results, with either autologous and allogeneic umbilical cord tissue MSCs. Preconditioning term MSCs might increase their turnover time in situations where a rapid yield of cells is needed for mitigating injury/inflammation in a short time frame (e.g., hypoxic ischemic injury or necrotizing enterocolitis). Future investigations should compare the reparative capability of WJ-MSCs after injuries that are commonly observed in the clinical setting (i.e., hyperoxia and mechanical stress from the ventilator, inflammation, and infection).

\section{Acknowledgments}

Data were generated in the Flow Cytometry Shared Resource Facility, which is supported by UT Health-Science Center at San Antonio (UTHSCSA), NIH-NCI P30 CA054174-20 (Cancer Therapy and Research Center at UTHSCSA) and UL1 TR001120 (Clinical and Translational Science Award).

\section{Disclosure Statement}

The authors declare no conflicts of interest and have nothing to disclose.

\section{Funding Sources}

The project described was supported by the National Center for Advancing Translational Sciences, National Institutes of Health (grant KL2 TR001118). The content is solely the responsibility of the authors and does not necessarily represent the official views of the NIH. This study was also supported by a UT Health-San Antonio School of Medicine Clinical Investigator Kickstart Pilot Grant.

\section{References}

Alt, E., Y. Yan, S. Gehmert, Y.-H. Song, A. Altman, S. Gehmert, et al. (2011): Fibroblasts share mesenchymal phenotypes with stem cells, but lack their differentiation and colony-forming potential. Biol Cell 103: 197-208.

Altaner, C., V. Altanerova, M. Cihova, L. Hunakova, K. Kaiserova, A. Klepanec, I. Vulev, J. Madaric (2013) Characterization of mesenchymal stem cells of "no-options" patients with critical limb ischemia treated by autologous bone marrow mononuclear cells. PLoS One 8: e73722.

Aly, H, L. Mohsen, N. Badrawi, H. Gabr, Z. Ali, D. Akmal (2012) Viability and neural differentiation of mesenchymal stem cells derived from the umbilical cord following perinatal asphyxia. J Perinatol 32: 671-676.
Antico Arciuch, V.G., M.E. Elguero, J.J. Poderoso, M.C. Carreras (2012) Mitochondrial regulation of cell cycle and proliferation. Antioxid Redox Signal 16: 1150-1180.

Arutyunyan, I, A. Elchaninov, A. Makarov, T. Fatkhudinov (2016a) Umbilical cord as prospective source for mesenchymal stem cellbased therapy. Stem Cells Int 2016: 6901286.

Arutyunyan, I., T. Fatkhudinov, E. Kananykhina, N. Usman, A. Elchaninov, A. Makarov, et al. (2016b) Role of VEGF-A in angiogenesis promoted by umbilical cord-derived mesenchymal stromal/stem cells: in vitro study. Stem Cell Res Ther 7: 46
Azandeh, S., M. Orazizadeh, M. Hashemitabar, A. Khodadadi, A.A. Shayesteh, D.B. Nejad, et al. (2012) Mixed enzymatic-explant protocol for isolation of mesenchymal stem cells from Wharton's jelly and encapsulation in 3D culture system. J Biomed Sci Eng 5: 580-586.

Bader, A.M., K. Klose, K. Bieback, D. Korinth, M. Schneider, M. Seifert, et al. (2015) Hypoxic preconditioning increases survival and proangiogenic capacity of human cord blood mesenchymal stromal cells in vitro. PLoS One 10: $\mathrm{e} 0138477$.

Boomsma, R.A., D.L. Geenen (2012) Mesenchymal stem cells secrete multiple cytokines that promote angiogenesis and have contrasting effects on chemotaxis and apoptosis. PLoS One 7: e35685. 
Boyette, L.B., O.A. Creasey, L. Guzik, T. Lozito, R.S. Tuan (2014) Human bone marrow-derived mesenchymal stem cells display enhanced clonogenicity but impaired differentiation with hypoxic preconditioning. Stem Cells Transl Med 3: 241-254.

Bustos, M.L., L. Huleihel, M.G. Kapetanaki, C.L. Lino-Cardenas, L. Mroz, B.M. Ellis, et al. (2014) Aging mesenchymal stem cells fail to protect because of impaired migration and antiinflammatory response. Am J Respir Crit Care Med 189: 787-798.

Chang, YS, Ahn SY, Yoo HS, Sung SI, Choi SJ, Oh W Il, et al. (2014) Mesenchymal stem cells for bronchopulmonary dysplasia: phase 1 doseescalation clinical trial. J Pediatr 164: $966-$ 972.e6.

Cotton, C.M., A.P. Murtha, R.N. Goldberg, C.A. Grotegut, P.B. Smith, R.F. Goldstein, et al. (2014) Feasibility of autologous cord blood cells for infants with hypoxic-ischemic encephalopathy. J Pediatr 164: 973-979.e1.

Cruz, FF, Rocco PRM (2015) Hypoxic preconditioning enhances mesenchymal stromal cell lung repair capacity. Stem Cell Res Ther 6: 130.

de Bruyn, D., M. Najar, G. Raicevic, N. Meuleman, K. Pieters, B. Stamatopoulos, et al. (2011) A rapid, simple, and reproducible method for the isolation of mesenchymal stromal cells from Wharton's jelly without enzymatic treatment. Stem Cells Dev 20: 547557.

do Carmo, A., I. Patrico, M.T. Curz, H. Carvalheiro, C.R. Oliveira, M.C. Lopes (2010) CXCL12/CXCR4 promotes motility and proliferation of glioma cells: Cancer Biology \&amp; Therapy 2010;9:56-65. Ann Neurosci 17: 85-86.

Duscher, D., R.C. Rennert, M. Januszyk, E. Anghel, Z.N. Maan, A.J. Whittam, et al. (2014) Aging disrupts cell subpopulation dynamics and diminishes the function of mesenchymal stem cells. Sci Rep 4: 7144.

Fei, M., W.-R. Xu, H. Qian, W. Zhu, Y.-M. Yan, Q.-X. Shao, H.-X. Xu (2010) Immunosuppressive effects of mesenchymal stem cells in collagen-induced mouse arthritis. Inflamm Res 59: 219-225.

Forraz, N., C.P. McGuckin (2011): The umbilical cord: a rich and ethical stem cell source to advance regenerative medicine. Cell Prolif 44(suppl 1): 60-69.

Franken, N.A,P., H.M. Rodermond, J. Stap, J. Haveman, C. van Bree C (2006): Clonogenic assay of cells in vitro. Nat Protoc 1: 23152319.

Ghafourifar, P, E. Cadenas (2005): Mitochondrial nitric oxide synthase. Trends Pharmacol Sci 26: 190-195.

Han, Y.-F., R. Tao, T.-J. Sun, J.-K. Chai, G. Xu, J. Liu (2013) Optimization of human umbilical cord mesenchymal stem cell isolation and culture methods. Cytotechnology 65: 819827.
Hass, R., C. Kasper, S. Böhm, R. Jacobs (2011): Different populations and sources of human mesenchymal stem cells (MSC): A comparison of adult and neonatal tissue-derived MSC. Cell Commun Signal 9: 12

Hermida-Gómez, T., I. Fuentes-Boquete, M.J. Gimeno-Longas, E. Muiños-López, S. Díaz-Prado, F.J. de Toro, et al. (2011) Quantification of cells expressing mesenchymal stem cell markers in healthy and osteoarthritic synovial membranes. J Rheumatol 38: 339-349.

Hoogduijn, M.J., M. Roemeling-van Rhijn, A.U. Engela, S.S. Korevaar, F.K. Mensah, et al. (2013) Mesenchymal stem cells induce an inflammatory response after intravenous infusion. Stem Cells Dev 22: 2825-2835.

Hua, J., J. Gong, H. Meng, B. Xu, L. Yao, M. Qian, et al. (2014): Comparison of different methods for the isolation of mesenchymal stem cells from umbilical cord matrix: proliferation and multilineage differentiation as compared to mesenchymal stem cells from umbilical cord blood and bone marrow. Cell Biol Int 38: 198-210.

Huang, R., D. Wu, Y. Yuan, X. Li, R. Holm, C.G. Trope, et al. (2014) CD117 expression in fibroblasts-like stromal cells indicates unfavorable clinical outcomes in ovarian carcinoma patients. PLoS One 9: e112209.

Hubbi, M.E., G.L. Semenza (2015) Regulation of cell proliferation by hypoxia-inducible factors. Am J Physiol Cell Physiol 309: C775C782.

Kim, J., Y. Piao, Y.K. Pak, D. Chung, Y.M. Han, J.S. Hong, et al. (2015) Umbilical cord mesenchymal stromal cells affected by gestational diabetes mellitus display premature aging and mitochondrial dysfunction. Stem Cells Dev 24: 575-586.

Krinner, A., M. Zscharnack, A. Bader, D. Drasdo, J. Galle (2009) Impact of oxygen environment on mesenchymal stem cell expansion and chondrogenic differentiation. Cell Prolif 42: 471-484.

Lan, Y.-W., K.-B. Choo, C.-M. Chen, T.-H. Hung, Y.-B. Chen, C.-H. Hsieh, et al. (2015) Hypoxia-preconditioned mesenchymal stem cells attenuate bleomycin-induced pulmonary fibrosis. Stem Cell Res Ther 6: 97.

Lavoie, P.M., Q. Huang, E. Jollette, M. Whalen, A.M. Nuyt, F. Audibert, D.P. Speert, T. Lacaze-Masmonteil, H. Soudeyns, T.R. Kollmann (2010) Profound lack of interleukin (IL)-12/ IL-23p40 in neonates born early in gestation is associated with an increased risk of sepsis. J Infect Dis 202: 1754-1763.

Li, J, T. Yawno, A. Sutherland, J. Loose, I. Nitsos, B.J. Allison, et al. (2017) Term vs. preterm cord blood cells for the prevention of preterm brain injury. Pediatr Res 82: 1030-1038.

Li, Z., C. Liu, Z. Xie, P. Song, R.C.H. Zhao, L. Guo, et al. (2011) Epigenetic dysregulation in mesenchymal stem cell aging and spontaneous differentiation. PLoS One 6: e20526.
Liang, C.-C., A.Y. Park, J.-L. Guan (2007) In vitro scratch assay: a convenient and inexpensive method for analysis of cell migration in vitro. Nat Protoc 2: 329-333.

Lim, R., S.T. Chan, J.L. Tan, J.C. Mockler, S.V. Murphy, E.M. Wallace (2013) Preterm human amnion epithelial cells have limited reparative potential. Placenta 34: 486-492.

Machová Urdzíková, L., J. Růžička, M. LaBagnara, et al. (2014) Human mesenchymal stem cells modulate inflammatory cytokines after spinal cord injury in rat. Int J Mol Sci 15: 11275-11293.

Mafi, P. (2011) Adult mesenchymal stem cells and cell surface characterization - a systematic review of the literature. Open Orthop J 5: 253 260.

Mao, F., W.R. Xu, H. Qian, W. Zhu, Y.M. Yan., Q. X. Shao, H.X. Xu (2010) Immunosuppressive effects of mesenchymal stem cells in collageninduced mouse arthritis. Inflamm Res 59: 219-225.

Markel, T.A., P.R. Crisostomo, M.C. Manukyan, D. Al-Azzawi, C.M. Herring, T. Lahm, et al. (2009) Are neonatal stem cells as effective as adult stem cells in providing ischemic protection? J Surg Res 152: 325-330.

Masalunga, C., H.J. Rozycki, E.S. Mainali (2007) The impact of hyperoxia on the neonatal and adult developing dendritic cell. Pediatr Res 62: 78-82.

Messerli, M., A. Wagner, R. Sager, M. Mueller, M. Baumann, D.V. Surbek, et al. (2013) Stem cells from umbilical cord Wharton's jelly from preterm birth have neuroglial differentiation potential. Reprod Sci 20: 1455-1464.

Mohyeldin, A., T.S. Garzón-Muvdi, A. QuiñonesHinojosa (2010) Oxygen in stem cell biology: a critical component of the stem cell niche. Cell Stem Cell 7: 150-161.

Moreira, A., Y. Alayli, S. Balgi, C. Winter, S. Kahlenberg, S. Mustafa, et al. (2017) Upcycling umbilical cords: bridging regenerative medicine with neonatology. J Matern Fetal Neonatal Med 27: 1-10.

Naaldijk, Y., A.A. Johnson, S. Ishak, H.J. Meisel, C. Hohaus, A. Stolzing (2015) Migrational changes of mesenchymal stem cells in response to cytokines, growth factors, hypoxia, and aging. Exp Cell Res 338: 97-104.

Panfoli, I., S. Ravera, M. Podestà, C. Cossu, L. Santucci, M. Bartolucci, et al. (2015) Exosomes from human mesenchymal stem cells conduct aerobic metabolism in term and preterm newborn infants. FASEB J 30: 1416-1424.

Pendyala, S., I.A. Gorshkova, P.V. Usatyuk, D. He, A. Pennathur, J.D. Lambeth, et al. (2009) Role of Nox 4 and Nox 2 in hyperoxia-induced reactive oxygen species generation and migration of human lung endothelial cells. Antioxid Redox Signal 11: 747-764.

Perez, A., J.M. Bellon, M.D. Gurbindo, M.A. Munoz-Fernandez (2010) Impairment of stimulation ability of very-preterm neonatal monocytes in response to lipopolysaccharide. Hum Immunol 71: 151-157. 
Podestà, M., M. Bruschettini, C. Cossu, F. Sabatini, M. Dagnino, O. Romantsik, et al. (2015) Preterm cord blood contains a higher proportion of immature hematopoietic progenitors compared to term samples. PLoS One 10: e0138680.

Ravera, S., M. Podestà, F. Sabatini, C. Fresia, M. Columbaro, S. Bruno, et al. (2017) Mesenchymal stem cells from preterm to term newborns undergo a significant switch from anaerobic glycolysis to the oxidative phosphorylation. Cell Mol Life Sci 75: 889-903.

Rostamzadeh, A., M. Anjomshoa, S. Kurd, J.-K. Chai, F. Jahangiri, M.A. Nilforoushzadeh, et al. (2015) The role of Wharton's jelly mesenchymal stem cells in skin reconstruction. J Skin Stem Cell 2: e60143.

Salehinejad, P., N.B. Alitheen, A.M. Ali, A.R. Omar, M. Mohit, E. Janzamin, et al. (2012) Comparison of different methods for the isolation of mesenchymal stem cells from human umbilical cord Wharton's jelly. In Vitro Cell Dev Biol Anim 48: 75-83.

Scott, M.A., V.T. Nguyen, B. Levi, A.W. James (2011) Current methods of adipogenic differentiation of mesenchymal stem cells. Stem Cells Dev 20: 1793-804.

Smith, J.R., K. Pfeifer, F. Petry, N. Powell, J. Delzeit, M.L. Weiss (2016) Standardizing umbilical cord mesenchymal stromal cells for translation to clinical use: selection of GMP-compliant medium and a simplified isolation method. Stem Cells Int 2016: 1-14.
Sullivan, S.E., S.L. Staba, J.A. Gersting, A.D. Hutson, D. Theriaque, R.D. Christensen, D.A. Calhoun (2002) Circulating concentrations of chemokines in cord blood, neonates and adults. Pediatr Res 51: 653-657.

Tatad, A.M., M. Nesin, J. Peoples, S. Cheung, et al. (2008) Cytokine expression in response to bacterial antigens in preterm and term infant cord blood monocytes. Neonatology 94: 8-15.

Turinetto, V, E. Vitale, C. Giachino (2016) Senescence in human mesenchymal stem cells: functional changes and implications in stem cell-based therapy. Int J Mol Sci 17: E1164.

Uno, K., C.A. Merges, R. Grebe, G.A. Lutty, T.W. Prow (2007) Hyperoxia inhibits several critical aspects of vascular development. Dev Dyn 236: 981-990.

Wakai, T., P. Narasimhan, H. Sakata, E. Wang, H. Yoshioka, H. Kinouchi, et al. (2016) Hypoxic preconditioning enhances neural stem cell transplantation therapy after intracerebral hemorrhage in mice. J Cereb Blood Flow Metab 36: 2134-2145.

Weiss, M.L., D.L. Troyer (2006) Stem cells in the umbilical cord. Stem Cell Rev 2: 155-162.

Wisgrill, L., S. Schüller, M. Bammer, A. Berger, A. Pollak, T.F. Radke, et al. (2014) Hematopoietic stem cells in neonates: any differences between very preterm and term neonates? PLoS One 9: e106717.
Wyrsch, A., V. dalle Carbonare, W. Jansen, E. Chklovskaia, C. Nissen, D. Surbek, et al. (1999) Umbilical cord blood from preterm human fetuses is rich in committed and primitive hematopoietic progenitors with high proliferative and self-renewal capacity. Exp Hematol 27: 1338-1345.

Xu, R., Y. Sun, Z. Chen, Y. Yao, G. Ma (2016) Hypoxic preconditioning inhibits hypoxia-induced apoptosis of cardiac progenitor cells via the PI3K/Akt-DNMT1-p53 pathway. Sci Rep 6: 30922.

Yachie A., N. Takano, K. Ohta, T. Uehara, S. Fujita, T. Miyawaki, N. Taniguchi (1992): Defective production of interleukin- 6 in very small premature infants in response to bacterial pathogens. Infect Immun 60: 749-753.

Yousefifard, M., F. Nasirinezhad, H. Shardi Manaheji, A. Janzadeh, M. Hosseini, M. Keshavarz, et al. (2016) Human bone marrow-derived and umbilical cord-derived mesenchymal stem cells for alleviating neuropathic pain in a spinal cord injury model. Stem Cell Res Ther 7: 36 .

Zhuang, Y., D. Li, J. Fu, Q. Shi, Y. Lu, X. Ju (2015) Comparison of biological properties of umbilical cord-derived mesenchymal stem cells from early and late passages: immunomodulatory ability is enhanced in aged cells. Mol Med Rep 11: 166-174. 